LBL-37201

$\mathrm{UC}-413$

\title{
Radioisotope Yields from 1.85-GeV Protons on Mo and 1.85- and 5.0-GeV Protons on Te
}

D.W. Bardayan ${ }^{1}$, A.F. Barghouty 2 , Y.D. Chan ${ }^{3}$, M.T.F. da Cruz ${ }^{3}$, A. García 3 , M.M. Hindi1, R.-M. Larimer ${ }^{3}$, K.T. Leko 3 , E.B. Norman 3 , D.F. Rossi ${ }^{3}$, R.G. Stokstad ${ }^{3}$, F.E. Wietfeldt ${ }^{3}$, and I.Zlimen ${ }^{3}$

(1)Physics Department, Tennessee Technological University Cookeville, TN 38505

(2) Physics Department, Roanoke College, Salem, VA 24153

${ }^{(3)}$ Nuclear Science Division, Lawrence Berkeley Laboratory, Berkeley, California 94720

May 1995

This work was supported in part by the Director, Office of Energy Research, Office of High Energy and Nuclear Physics, Division of High Energy Physics, of the U.S. Department of Energy under Contract No. DE-AC03$76 \mathrm{SF} 00098$. 


\section{DISCLAIMER}

This report was prepared as an account of work sponsored by an agency of the United States Government. Neither the United States Government nor any agency thereof, nor any of their employees, make any warranty, express or implied, or assumes any legal liability or responsibility for the accuracy, completeness, or usefulness of any information, apparatus, product, or process disclosed, or represents that its use would not infringe privately owned rights. Reference herein to any specific commercial product, process, or service by trade name, trademark, manufacturer, or otherwise does not necessarily constitute or imply its endorsement, recommendation, or favoring by the United States Government or any agency thereof. The views and opinions of authors expressed herein do not necessarily state or reflect those of the United States Government or any agency thereof. 


\section{DISCLAIMER}

Portions of this document may be illegible in electronic image products. Images are produced from the best available original document. 


\title{
Radioisotope Yields from 1.85-GeV Protons on Mo and 1.85- and 5.0-GeV Protons on Te
}

D. W. Bardayan ${ }^{1, a}$, A. F. Barghouty ${ }^{2}$, Y. D. Chan ${ }^{(3)}$, M. T. F. da Cruz ${ }^{3, b}$, A. García ${ }^{3, c}$, M.M. Hindi ${ }^{1}$, R.-M. Larimer ${ }^{3}$, K. T. Lesko ${ }^{3}$, E. B. Norman ${ }^{3}$, D. F. Rossi ${ }^{3, d}$, R. G. Stokstad ${ }^{3}$, F. E. Wietfeldt ${ }^{3, e}$ and I. Žlimen ${ }^{3}$

${ }^{1}$ Physics Department, Tennessee Technological University, Cookeville, TN 38505, USA

${ }^{2}$ Physics Department, Roanoke College, Salem, VA 24153, USA

${ }^{3}$ Nuclear Science Division, Lawrence Berkeley Laboratory, Berkeley, CA 94720, USA

\begin{abstract}
Radioisotope yields from $1.85-\mathrm{GeV}$ proton interactions in a natural isotopic composition Mo target and those from $1.85-$ and $5.0-\mathrm{GeV}$ protons in natural $\mathrm{Te}$ targets were measured at Lawrence Berkeley Laboratory's Bevatron. The radioisotope yields were determined by $\gamma$-counting the targets using a $100-\mathrm{cm}^{3}$ coaxial $\mathrm{Ge}$ detector following the irradiations. Cross sections were determined for the production of 31 radioactive nuclides, ranging from $Z=35, A=74$, to $Z=43, A=97$, from the Mo target and for 47 radioactive nuclides, ranging from $Z=35, A=75$, to $Z=53, A=130$ from the Te targets.
\end{abstract}

\section{Introduction}

Cross sections for high-energy proton-induced reactions on medium to heavy weight nuclei are important for the calculation of cosmic ray transport, the confinement time of cosmic rays in the Galaxy and for the calculation of cosmicray-induced reactions in meteorites, lunar surfaces, and in terrestrial materials. Among the most abundant elements above $Z=40$ are molybdenum and tellurium. With the aim of providing cross sections which would be useful for calibrating and extending the range of semi-empirical calculations into the medium-heavy element range, we measured the radioisotope yields from 1.85$\mathrm{GeV}$ proton interactions in a natural isotopic composition Mo target and those from 1.85- and 5.0-GeV protons in natural Te targets at Lawrence Berkeley Laboratory's Bevatron.

\section{Experiment}

The Mo and Te targets were disks of diameter $3.1 \mathrm{~cm}$ and each a thickness of $0.67 \mathrm{~cm}$ for the $1.85-\mathrm{GeV}$ irradiation and the Te target was $5.1 \mathrm{~cm} \times 5.1 \mathrm{~cm}$ with 
a thickness of $1.0 \mathrm{~cm}$ for the $5.0-\mathrm{GeV}$ irradiation. The targets were bombarded with protons from the LBL Bevatron accelerator. The irradiation was performed with the targets in air, and with the Mo and Te slabs assembled in a stack, together with Polycast Acrylic sheets (polymethyl methacrylate, $\left[\mathrm{C}_{5} \mathrm{O}_{2} \mathrm{H}_{8}\right]_{n}$ ). These plastic sheets served to monitor the integrated beam exposure, through the production of ${ }^{11} \mathrm{C}$, from the $\mathrm{C}$ and $\mathrm{O}$ contents of the plastic $[1,2]$. The bombardment times were approximately $1 \mathrm{~h}$ each, with integrated currents of $60 \mathrm{nC}$ and $5 \mathrm{nC}$, respectively, for the $1.85-\mathrm{GeV}$ and $5.0-\mathrm{GeV}$ irradiations.

Following the irradiation, $\gamma$ rays from each of the targets were counted (separately) with a $100 \mathrm{~cm}^{3}$ coaxial $\mathrm{HPGe}$ detector inside a $5-\mathrm{cm}$ thick lead shielding. Due to the widely different half-lives of the isotopes under study, we used three different lengths of time bins for counting: 5-min bins during the first two hours, 1-hour bins during the next 48 hours, and then a series of five 6 -hours bins. A 1-h spectrum from the $\mathrm{p}+$ Mo irradiation is shown in Fig. 1.

\section{Data Analysis and Results}

The photo peak yields of characteristic $\gamma$-rays of each isotope were extracted using a peak fitting routine. At least two $\gamma$-ray lines were used for each isotope, when possible. After correcting for the detector efficiency, self absorption in the target, summing and dead-time effects, the time-dependent yields of each $\gamma$-ray line were fit to determine initial activities. In some cases the time yields could be fit with two time components, thus allowing the extraction of the contribution of a parent nuclide to a daughter. Effective cross sections for the production of each isotope were calculated from a knowledge of the deduced yields at the end of the irradiation, the average proton flux and the duration of the irradiation.

Table 1 shows the measured effective cross-sections for radioisotopes produced in the $\mathrm{p}+\mathrm{Te}$ bombardment at 1.85 and $5.0 \mathrm{GeV}$, and Table 2 shows the cross sections for isotopes produced in $\mathrm{p}+\mathrm{Mo}$ bombardment at $1.85 \mathrm{GeV}$. In those cases in which we determined the yield of a parent the direct production of the daughter isotope by spallation could be deduced. The cross section for such isotopes is marked as being direct in the Tables. A theoretical calculation

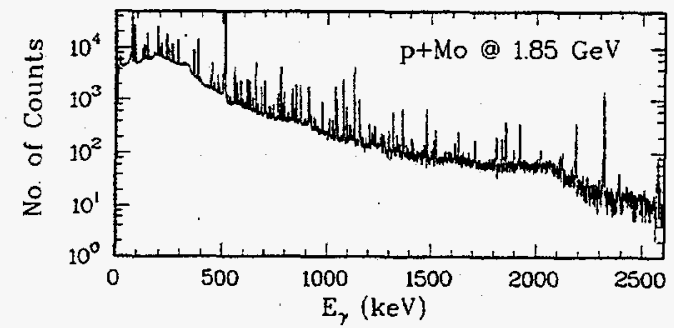

Fig 1: One-hour $\gamma$-ray spectrum from Mo target after one hour of irradiation with 1.85-GeV protons. 
Table 1: Effective cross-sections for $1.85-$ and $5.0-\mathrm{GeV}$ protons on natural Te

\begin{tabular}{|c|c|c|c|c|c|}
\hline Isotope & $\begin{array}{c}1.85 \mathrm{GeV} \\
\sigma(\mathrm{mb})^{\mathrm{a}}\end{array}$ & $\begin{array}{l}5.0 \mathrm{GeV} \\
\sigma(\mathrm{mb})^{\mathrm{a}}\end{array}$ & Isotope & $\begin{array}{c}1.85 \mathrm{GeV} \\
\sigma(\mathrm{mb})^{\mathrm{a}}\end{array}$ & $\begin{array}{l}5.0 \mathrm{GeV} \\
\sigma(\mathrm{mb})^{\mathrm{a}}\end{array}$ \\
\hline${ }^{24} \mathrm{Na}$ & $\overline{0.91(4)}$ & $4.4(2)$ & ${ }^{111} \mathrm{Cd}^{m}$ & $\overline{5.5(2)}$ & $7.0(1)$ \\
\hline${ }^{75} \mathrm{Br}$ & $1.30(3)$ & $2.12(16)$ & ${ }^{116} \mathrm{Sb}^{m}$ & $5.6(2)$ & $6.2(6)$ \\
\hline${ }^{76} \mathrm{Br}$ & $2.8(2)$ & $3.7(3)$ & ${ }^{117} \mathrm{Sb}$ & $30(2)^{b}$ & $38(2)^{\mathrm{b}}$ \\
\hline${ }^{77} \mathrm{Br}$ & $4.6(2)$ & $7.2(3)$ & ${ }^{118} \mathrm{Sb}$ & $8.26(3)$ & $12.2(4)$ \\
\hline${ }^{82} \mathrm{Rb}^{m}$ & $3.3(1)^{b}$ & $4.1(2)^{b}$ & ${ }^{120} \mathrm{Sb}^{m}$ & $10.2(5)$ & $15.7(5)$ \\
\hline${ }^{84} \mathrm{Rb}^{m}$ & $1.4(3)^{\mathrm{b}}$ & $2.3(2)^{b}$ & ${ }^{122} \mathrm{Sb}$ & $18.8(2)$ & $32(2)$ \\
\hline${ }^{87} \mathrm{Sr}^{m}$ & $0.08(13)^{b}$ & 1 & ${ }^{126} \mathrm{Sb}$ & $4.8(4)^{\mathrm{b}}$ & $7.9(3)^{\mathrm{b}}$ \\
\hline${ }^{85} \mathrm{Y}$ & $0.9(5)$ & - & ${ }^{126} \mathrm{Sb}^{m}$ & $7.0(2)$ & $10.4(2)$ \\
\hline${ }^{86} \mathrm{Y}^{m}$ & $5.2(1)^{b}$ & $6.1(1)^{b}$ & ${ }^{127} \mathrm{Sb}$ & $11.8(4)$ & $23(1)$ \\
\hline${ }^{86} \mathrm{Y}$ & $19(1)^{b}$ & $23(1)^{\mathrm{b}^{\prime}}$ & ${ }^{128} \mathrm{Sb}$ & $2.8(6)$ & $3.7(2)$ \\
\hline${ }^{87} Y^{m}$ & $3.0(13)^{b}$ & $2.2(37)^{b}$ & ${ }^{128} \mathrm{Sb}^{m}$ & $3.1(2)$ & $3.5(6)$ \\
\hline${ }^{87} \mathrm{Y}$ & $0.55(33)^{b}$ & - & ${ }^{129} \mathrm{Sb}$ & $5.6(2)$ & $8.8(8)$ \\
\hline${ }^{90} \mathrm{Y}^{m}$ & $0.78(3)$ & $0.76(7)$ & ${ }^{123} \mathrm{Sn}$ & $1.65(7)$ & $2.93(15)$ \\
\hline${ }^{86} \mathrm{Zr}$ & $2.1(1)$ & $2.8(1)$ & ${ }^{117} \mathrm{Te}$ & $4.6(3)$ & $5.5(3)$ \\
\hline${ }^{87} \mathrm{Zr}$ & $7.2(1)$ & $10(2)$ & ${ }^{119} \mathrm{Te}^{m}$ & $9.2(7)$ & $9.9(6)$ \\
\hline${ }^{90} \mathrm{Nb}$ & $8.8(4)$ & $7.6(4)$ & ${ }^{119} \mathrm{Te}$ & $4.31(15)$ & $6.1(5)$ \\
\hline${ }^{97} \mathrm{Ru}$ & $9.9(2)$ & $9.7(3)$ & ${ }^{121} \mathrm{Te}^{m}$ & $14(4)^{\mathrm{b}}$ & $22(2)^{b}$ \\
\hline${ }^{100} \mathrm{Rh}$ & $6.8(5)$ & $6.2(2)$ & ${ }^{121} \mathrm{Te}$ & $8.3(4)^{b}$ & $9.5(4)^{b}$ \\
\hline${ }^{104} \mathrm{Ag}$ & $5.6(4)$ & $4.2(4)$ & ${ }^{129} \mathrm{Te}$ & $25(1)^{b}$ & $52(3)^{\mathrm{b}}$ \\
\hline${ }^{104} \mathrm{Ag}^{m}$ & $4.7(2)$ & $4.7(3)$ & ${ }^{121} I$ & $3.7(1)^{\mathrm{b}}$ & $6.2(2)^{\mathrm{b}}$ \\
\hline${ }^{107} \mathrm{In}$ & $2.6(4)$ & $2.0(2)$ & ${ }^{123} \mathrm{I}$ & $9.0(2)^{\mathrm{b}}$ & $11.7(3)^{b}$ \\
\hline${ }^{108} \mathrm{In}^{m}$ & $3.2(1)$ & $2.7(2)$ & ${ }^{124} \mathrm{I}$ & $9.4(3)^{b}$ & $15.2(5)^{b}$ \\
\hline${ }^{108} \mathrm{In}$ & $1.2(1)$ & - & ${ }^{126} \mathrm{I}$ & $6.9(23)^{b}$ & 15. $(6)^{b}$ \\
\hline${ }^{109}$ In & 9.1(1) & $8.0(4)$ & ${ }^{128} I$ & $5.7(4)^{6}$ & $10(2)^{b}$ \\
\hline${ }^{110} \mathrm{In}^{\mathrm{m}}$ & $4.1(2)$ & $7.3(3)$ & ${ }^{130} I$ & $3.0(1)^{\mathrm{b}}$ & $4.6(9)^{b}$ \\
\hline${ }^{110} \mathrm{In}$ & $5.7(2)$ & $4.4(1)$ & & & \\
\hline${ }^{111} \mathrm{In}$ & $14.6(3)^{b}$ & $16.4(4)^{b}$ & & & \\
\hline${ }^{116} \mathrm{In}^{m}$ & $4.3(3)$ & $5.9(5)$ & & & \\
\hline
\end{tabular}

${ }^{2}$ Errors shown are statistical. There is an additional $10 \%$ error in the overall normalization of the cross-sections.

${ }^{b}$ Direct production cross-section.

of the effective cross sections was made using the semi-empirical formula given by Silberberg and Tsao [3], but these are not shown here due to lack of space. The median deviation from the experimental cross sections was about $60 \%$.

\section{Acknowledgments}

We wish to thank the Di-Lepton Spectrometer Group, for the use of the Bevatron facility for the high-energy proton activations. This work was supported 
Table 2: Effective cross-sections for $1.85-\mathrm{GeV}$ protons on natural Mo

\begin{tabular}{|c|c|c|c|c|c|}
\hline Isotope & $\sigma(\mathrm{mb})^{\mathrm{a}}$ & Isotope & $\sigma(\mathrm{mb})^{\mathrm{a}}$ & Isotope & $\sigma(\mathrm{mb})^{\mathrm{a}}$ \\
\hline${ }^{93} \mathrm{Tc}$ & $2.70(2)$ & ${ }^{86} \mathrm{Zr}$ & $8.1(2)$ & ${ }^{78} \mathrm{Rb}$ & $1.69(15)$ \\
\hline${ }^{95} \mathrm{Tc}^{m}$ & $2.0(5)^{b}$ & ${ }^{89} \mathrm{Zr}$ & $14.7(1.7)^{\mathrm{b}}$ & ${ }^{79} \mathrm{Rb}$ & $5.1(6)$ \\
\hline${ }^{90} \mathrm{Mo}$ & $7.1(4)$ & ${ }^{95} \mathrm{Zr}$ & $2.0(2)^{b^{\prime}}$ & ${ }^{81} \mathrm{Rb}$ & $15.9(7)^{b}$ \\
\hline${ }^{93} \mathrm{Mo}^{m}$ & $2.8(1)^{\mathrm{b}}$ & ${ }^{97} \mathrm{Zr}$ & $2.10(5)^{b}$ & ${ }^{82} \mathrm{Rb}^{\mathrm{m}}$ & $9.6(3)^{b}$ \\
\hline${ }^{88} \mathrm{Nb}$ & $3.9(2)$ & ${ }^{84} \mathrm{Y}$ & $7.2(2)$ & ${ }^{84} \mathrm{Rb}^{m}$ & $2.4(6)^{b}$ \\
\hline${ }^{89} \mathrm{Nb}^{m}$ & $18(1)$ & ${ }^{85} \mathrm{Y}$ & $5.9(2)^{b}$ & ${ }^{76} \mathrm{Kr}$ & $2.5(2)$ \\
\hline${ }^{90} \mathrm{Nb}$ & $26.2(8)^{b}$ & ${ }^{86} \mathrm{Y}$ & $15.8(6)$ & ${ }^{77} \mathrm{Kr}$ & $4.58(15)$ \\
\hline${ }^{91} \mathrm{Nb}^{m}$ & $18(3)$ & ${ }^{87} \mathrm{Y}$ & $44(1)$ & ${ }^{79} \mathrm{Kr}$ & $12.4(7)^{b}$ \\
\hline${ }^{92} \mathrm{Nb}^{m}$ & $13.6(5)^{b}$ & ${ }^{90} Y^{m}$ & $2.36(8)$ & ${ }^{74} \mathrm{Br}^{m}$ & $2.75(11)^{\mathrm{b}}$ \\
\hline${ }^{95} \mathrm{Nb}$ & $18.5(9)^{b}$ & ${ }^{80} \mathrm{Sr}$ & $5.3(2)$ & ${ }^{75} \mathrm{Br}$ & $8.7(3)$ \\
\hline${ }^{95} \mathrm{Nb}^{m}$ & $5.0(4)^{b}$ & ${ }^{81} \mathrm{Sr}$ & $3.8(2)$ & ${ }^{76} \mathrm{Br}$ & $10.1(9)^{b}$ \\
\hline${ }^{96} \mathrm{Nb}$ & $11.2(5)^{b}$ & ${ }^{83} \mathrm{Sr}$ & $18.6(6)$ & ${ }^{77} \mathrm{Br}$ & $4.17(13)$ \\
\hline${ }^{97} \mathrm{Nb}$ & $9.9(5)^{b}$ & & & & \\
\hline
\end{tabular}

${ }^{2}$ Errors shown are statistical. There is an additional $10 \%$ error in the overall normalization of the cross-sections.

${ }^{b}$ Direct production cross-section.

by the U.S. Department of Energy, Nuclear Physics Division, via grants No. DE-AC03-76SF00098 and DE-FG05-87ER40314. M.T.F. da Cruz was supported by Fundação de Amparo à Pesquisa do Estado de São Paulo, FAPESP, São Paulo, Brasil.

\section{References}

[a] Present address: Physics Dept. , Yale Univ., New Haven, CT, USA.

[b] Present Address: Instituto de Física, Universidade de São Paulo, Caixa Postal 20516, 01498 São Paulo, SP, Brasil.

[c] Present address: Physics Dept., Notre Dame Univ., South Bend, IN, USA

[d] DOE-TRAC fellow at Lawrence Berkeley Laboratory, July-August 1992.

[e] Present address: Nat. Inst. of Sci. and Tech. , Gaithersburg, MD, USA.

[1] Smith A. R., et al., Phys. Rev. C28 (1983) 1614.

[2] Olson D. L., et al., Phys. Rev. C28, (1983) 1602.

[3] Siberberg R. and C. H. Tsao, Phys. Rep. 191 (1990) 351. 